\title{
MODULATION OF POTASSIUM CURRENT KINETICS IN BAG CELL NEURONS OF APLYSIA BY AN ACTIVATOR OF ADENYLATE CYCLASE ${ }^{1}$
}

\author{
JUDITH A. STRONG ${ }^{2}$ \\ Department of Physiology, Yale University School of Medicine, New Haven, Connecticut 06510
}

Received January 17, 1984; Revised June 13, 1984; Accepted June 15, 1984

\begin{abstract}
The bag cell neurons of Aplysia are neurosecretory cells which control egg-laying behavior. In their resting state, the cells have a high resting potential and show no spontaneous activity. In response to brief stimulation of a neural input, the cells depolarize and fire repetitively for up to $60 \mathrm{~min}$. This afterdischarge is thought to be controlled by elevations of intracellular adenosine $3^{\prime}: 5^{\prime}$-monophosphate (cAMP). A voltage clamp study of bag cells in primary culture was undertaken in order to characterize the effects of cAMP on the cells' electrical properties. The transient outward potasssium current (A-current) was studied before and after the application of forskolin (an activator of adenylate cyclase) and RO20-1724 (a phosphodiesterase inhibitor). These drugs reduced the amplitude of the A-current, primarily by speeding the inactivation process. The time constants for inactivation were speeded at all potentials, but the largest effects were seen at the more positive potentials $(-40$ to $-15 \mathrm{mV})$, where the time constants were reduced 5 -fold. Neither the activation process nor the steadystate parameters of inactivation were altered by the drugs. It is suggested that these changes in the A-current could explain the ability of the bag cells to fire repetitively during the afterdischarge.
\end{abstract}

In most excitable tissues, the threshold and shape of the action potential are influenced by a variety of voltage- and calcium-dependent ion currents. For most of these currents, at least one example is known of the modulation of that current by a hormone or neurotransmitter. Modulation was first well characterized in cardiac tissue, where the calcium current is enhanced by an adrenalin-sensitive adenylate cyclase (for review, see Reuter, 1983). More recently, examples of the modulation of the inward (anomalous) rectifier (e.g., Levitan and Adams, 1981) and the calcium-activated potassium current (e.g., Madison and Nicoll, 1982) have been found in a variety of vertebrate and invertebrate neurons. Several new channels have been discovered during investigations of neuromodulatory phenomena. These include the M-channel, which is turned off by muscarine in bullfrog sympathetic neurons (Adams et al., 1982), and a potassium channel which is turned off by a serotonin-linked adenylate cyclase in sensory neurons of Aplysia (Siegelbaum et al., 1982). Modulation of ionic channels differs from the kind of transmitter action typified by the action of acetylcholine at the neuromuscular junction. The latter event

\footnotetext{
${ }^{1}$ This work was supported by National Institutes of Health Grants NS 12961 (to Dr. C. F. Stevens) and NS 18492 (to L. K. Kaczmarek). Some of the results presented here were submitted in partial fulfillment of requirements for the Ph.D. degree from Yale University. I am grateful to R. Aldrich, M. B. Boyle, L. K. Kaczmarek, J. E. Lisman, C. F. Stevens, and G. Yellen for comments on the manuscript and for helpful discussions. I thank S. A. DeRiemer, I. K. Kaczmarek, I. R. Levitan, and F. Strumwasser for permission to quote unpublished results.

${ }^{2}$ Present address: Department of Pharmacology, Yale University School of Medicine, New Haven, CT 06510.
}

occurs on a millisecond time scale and results from a direct interaction of the transmitter with an ion channel (the acetylcholine receptor). The modulatory events mentioned above are in general thought to occur through a second-messenger mechanism, and they occur on a much slower (seconds to hours) time scale. (For reviews of modulation, see Kehoe and Marty, 1980; Siegelbaum and Tsien, 1983.)

The bag cell neurons of $\Lambda$ plysia provide an interesting model system in which to study long-lasting changes in excitability. These neurosecretory cells form two clusters at the base of each pleuroabdominal connective and are responsible for controlling egg-laying behavior in the animal. In their resting state, the cells have high resting potentials and are electrically silent. They can fire an action potential when depolarized with injected current, but the firing is not repetitive (Kupferman and Kandel, 1970). In response to peptides from the reproductive tract (Heller et al., 1980), or in response to a brief (15 sec) electrical stimulation of the pleuroabdominal connectives (Kupferman and Kandel, 1970), the cells depolarize and fire action potentials repetitively. This period of intense electrical activity, called an afterdischarge, lasts for 20 to $60 \mathrm{~min}$. The action potentials seen during the afterdischarge have an enhanced height and width compared to the action potential which can be elicited in the resulting cells. During the afterdischarge, the cells release peptides (including their primary product, egg-laying hormone), which, through multiple actions on other neurons and on reproductive organs, lead to a complex pattern of behavior culminating in egg-laying (Strumwasser et al., 1980).

Adenosine $3^{\prime}: 5^{\prime}$-monophosphate (cAMP) controls at least some of the electrical events of the afterdischarge: during the 
afterdischarge, cAMP levels increase by up to $200 \%$. The time course of the changes in cAMP concentration is well correlated with the pattern of action potential enhancement seen during the afterdischarge (Kaczmarek et al., 1978). Afterdischarges may be initiated by any of a number of cAMP analogues, and phosphodiesterase inhibitors (PDIs) can prolong an afterdischarge. Several bag cell proteins which are substrates for endogenous cAMP-dependent protein kinase are also phosphorylated during the afterdischarge (Jennings et al., 1982). Finally, intracellular injection of the catalytic subunit of cAMP. dependent protein kinase into isolated, cultured bag cells causes an enhancement of the action potential similar to that seen during the course of an afterdischarge (Kaczmarek et al., 1980).

The bag cells are large (50 to $120 \mu \mathrm{m}$ in diameter) and hence suitable for electrophysiological studies. In the intact bag cell cluster, the cells seem to be extensively coupled by gap junctions (Kaczmarek et al., 1979) and have fairly long processes, making voltage clamp analysis difficult. However, the cells may be isolated and put into primary cell culture. The cultured cells retain many of the electrical characteristics of the intact cells, including the ability to afterdischarge in response to cAMP analogues (Kaczmarek and Strumwasser, 1981). It is much easier to use the voltage clamp technique on the cultured cells, because they do not have extensive processes (if examined within a few days of culturing) and because isolated cells which are not electrically coupled to other cells can be selected for study.

It is not yet known how elevated cAMP levels might cause the profound changes in excitability seen during an afterdischarge. In this paper, I have approached this problem by doing voltage clamp studies of the cultured bag cells. I have used extracellular application of the adenylate cyclase activator forskolin (Seamon et al., 1981), along with PDIs, to elevate intracellular cAMP levels, and have studied the effects of these drugs on the transient outward currents (A-currents).

Transient outward currents were first seen in marine eggs (Hagiwara et al., 1961) and have been described in a number of preparations (for review, see Thompson and Aldrich, 1980). These potassium currents have kinetic properties similar to those of the sodium currents of nerve (Hodgkin and Huxley, 1952 ) in that depolarization to an appropriate potential causes the A-current to activate and then inactivate. The predominant role of the A-current seems to be in determining the behavior of the cell near threshold and, especially, during the interspike interval of repetitively firing cells (Connor and Stevens, 1971b; Connor, 1978).

In this paper I report that the application of forskolin and PDIs to the cultured bag cells markedly speeds up the inactivation kinetics of the A-current at all potentials, while having little effect on the steady-state parameters of inactivation or on the activation process.

\section{Materials and Methods}

Animals and cell culture. Aplysia californica were obtained from Alacrity Marine Services (Redondo Beach, CA) and kept at $14^{\circ} \mathrm{C}$. The methods used for primary culture of the bag cells were similar to those described by Kaczmarek and Strumwasser (1981). Briefly, the abdominal ganglion was removed from the animal and incubated at room temperature in a solution of ncutral protease $(1.25 \%$ for $18 \mathrm{hr}$ or $2.5 \%$ for $6 \mathrm{hr}$ ), the bag cell cluster was isolated and desheathed, and the cells were separated by gentle trituration and seeded into plastic tissue culture dishes containing Eagle's minimum essential medium (MEM) (see below). The cells were kept at $14^{\circ} \mathrm{C}$. Sometimes cells were transferred after 1 or 2 days to $12^{\circ} \mathrm{C}$, in order to slow the growth of the neural processes.

Voltage clamp and intracellular dialysis. Kostyuk et al. (1975) and Akaike et al. (1978) have described techniques for the intracellular dialysis of neurons. This method allows ionic and pharmacological manipulation of the intracellular environment, as well as providing a low resistance electrical access to the cell which facilitates voltage clamping.

I have developed an intracellular dialysis technique for use in the cultured bag cells. This technique was originally selected to facilitate the separation and characterization of the several different ionic currents present in these cells. However, in the present study, the Acurrents were isolated from other currents by using voltage pulses more negative than $-15 \mathrm{mV}$ (see below). Therefore, the intracellular dialysis technique was used here primarily to provide a good voltage clamp.

The method used for intracellular dialysis of the bag cells was adapted from the patch clamp technique described by Hamill et al. (1981). In the configuration which they describe for making whole cell recordings from small cells, a polished glass pipette is placed on the cell, gentle suction is applied to cause formation of a high resistance seal (a "gigaseal") between the glass and the membrane, and further suction is applied to rupture the cell membrane spanning the pipette orifice. I have modified this technique for use in the much larger cultured bag cells. The differences between my technique and that used by Hamill et al. (1981) are as follows.

1. I used much larger patch pipettes. These had an inner diameter of about $5 \mu \mathrm{m}$ and resistances of 0.2 to 0.3 megohm in seawater.

2. The seals formed sometimes had resistances as high as 1 or 2 gigohms, but values of 100 to 500 megohms were more common. This is in contrast to the much higher resistance values seen when smaller pipettes are used.

3. Hamill et al. (1981) used chloridized silver wires to connect the inside of the patch pipette to the voltage clamp amplifier and to connect the bath to the circuit ground. As shown in Figure 1, I have replaced these two wires with $3 \mathrm{M} \mathrm{KCl}$ electrodes. These electrodes were constructed from glass tubing fire polished at one end to a diameter of 15 to $20 \mu \mathrm{m}$. The glass tube was filled with $3 \mathrm{M} \mathrm{KCl}$, a chloridized silver wire was inserted into the other (non-fire-polished) end, and an airtight epoxy seal was formed between the silver wire and the glass. (This sealing was necessary so that application of suction to the interior of the patch pipette would not cause any bulk flow of $3 \mathrm{M} \mathrm{KCl}$ from the electrode into the pipette.) At the beginning of an experiment both electrodes were placed in the bath solution and "zeroed" (i.e., a correction potential was added to the command potential so that zero current flowed at a nominal command potential of $0 \mathrm{mV}$ ). At the end of the experiment this procedure was repeated in order to check for drift in the electrodes' junction potentials. Usually, the electrodes drifted no more than 1 or $2 \mathrm{mV}$ during an experiment, and no data have been presented from cells with a drift greater than $4 \mathrm{mV}$. I used $3 \mathrm{M} \mathrm{KCl}$ electrodes so that I could change solutions in the pipette or in the bath without causing changes in the junction potential at the electrode/ solution interface. A second advantage of the $3 \mathrm{M} \mathrm{KCl}$ electrodes was that they eliminated the need to measure and correct for the liquid junction potential between the internal and external solutions.

4. The time required for exchange of small ions between the pipette and the cytosol was 10 to 20 min (estimated from experiments in which

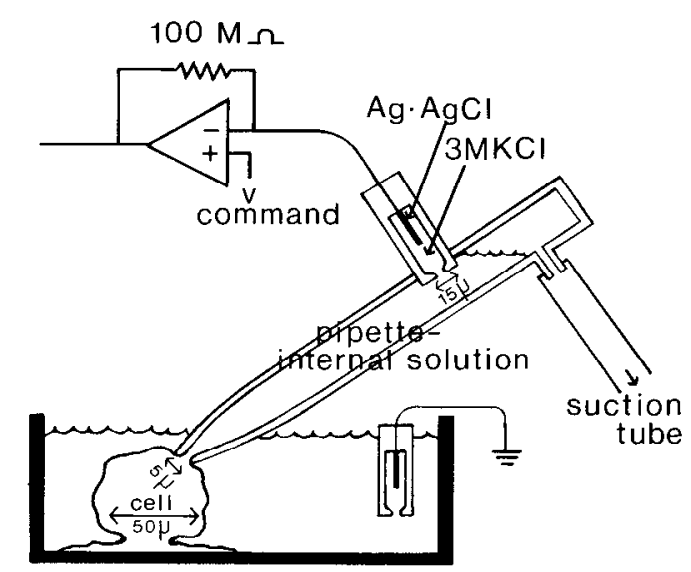

Figure 1. Schematic diagram of the experimental apparatus. Sealed $3 \mathrm{M} \mathrm{KCl} \mathrm{Ag-AgCl} \mathrm{electrodes} \mathrm{connect} \mathrm{the} \mathrm{inside} \mathrm{of} \mathrm{the} \mathrm{pipette} \mathrm{to} \mathrm{the}$ patch clamp amplifier and the bath to the circuit ground. After an electrical seal has formed between the pipette and the cell membrane, the membrane spanning the pipette is ruptured with suction, creating a low-resistance pathway from the internal solution to the cytosol. 
potassium channel blockers or altered potassium concentrations were used in the pipette solution). This is much longer than the exchange time of tens of seconds reported by Hamill et al. (1981), in the smaller cells used in their study. Unless otherwise noted, recordings were not made until the measured currents had stabilized and at least $10 \mathrm{~min}$ had passed since the beginning of the dialysis (i.e., since the rupture of the cell membrane). I avoided using cells which had grown out extensive processes, as these cells could take much longer to stabilize. During this period of stabilization, the calcium-activated potassium currents disappeared (possibly because the solution in the pipette contained EGTA) and, as has been reported by others working with dialyzed cells, the calcium currents became much smaller (Kostuk et al., 1984). However, the A-currents changed very little during this stabilization period.

Data acquisition and analysis. The voltage clamp was the virtual ground type commonly used for patch-clamp recording. The feedback resistor had a value of 100 megohms. Usually, no series resistance compensation was used. Currents were amplified filtered at $2500 \mathrm{~Hz}$, and then digitized and recorded by an LSI 11/23 laboratory computer. The computer was also used to control the voltage stimuli and to analyze the data. When it was necessary to fit the data with the sum of two exponential functions, the following method was used. Amplitudes and time constants of the two exponentials were fit by eye. The parameters of the fit were adjusted while the current and the fitted exponential were displayed in both linear and semilog plots, appearing much as they do in Figure 5. This method allows the more accurate determination of the time constant possible in a semilog plot along with the more accurate determination of amplitude afforded by a linear plot. Figures have been reproduced from ink tracings made on a Hewlett Packard 7470A plotter under control of the computer. Current samples contained 256 or 512 points; in the figures the plotter has connected these points with straight lines. In each record, the current required to clamp the cell to the holding potential has been subtracted. In some records, linear leak subtraction has been used; this is noted in the figure legends. The interval between the depolarizing voltage pulses was 10 sec.

Solutions. The artificial seawater (ASW) used in the bath had the following composition: $460 \mathrm{mM} \mathrm{NaCl}, 10.4 \mathrm{mM} \mathrm{KCl}, 15 \mathrm{mM}$ HEPES $11 \mathrm{mM} \mathrm{CaCl}_{2}, 27 \mathrm{mM} \mathrm{MgCl}, 28 \mathrm{mM} \mathrm{MgSO}, 1 \mathrm{mg} / \mathrm{ml}$ of glucose $(\mathrm{pH}$ adjusted to 7.8 ).

The culture medium (MEM) was made by adding essential and nonessential amino acids, vitamins, glutamine, penicillin, streptomyocin (Grand Island Biological Co., Grand Island, NY), and $13 \mathrm{~mm}$ $\mathrm{NaHCO}_{3}$ to the ASW (Kaczmarek and Strumwasser, 1981).

The internal solution used in the pipette contained: $553 \mathrm{mM}$ potassium aspartate, $17 \mathrm{mM} \mathrm{KH}_{2} \mathrm{PO}_{4}, 10 \mathrm{mM}$ HEPES, $10 \mathrm{~mm}$ reduced glutathione, $5 \mathrm{mM} \mathrm{MgCl}, 1 \mathrm{mg} / \mathrm{ml}$ of glucose, $5 \mathrm{~mm}$ ATP (Sigma, grade II disodium salt), $0.1 \mathrm{mM}$ GTP (Sigma, type 3 disodium salt), $0.2 \mathrm{mM}$ FGTA ( $\mathrm{pH}$ adjusted to 7.3). The glutathione, glucose, and nucleotides were included based on the work of Stern and Lisman (1982). There was no systematic study of the effects of varying the components of the internal solutions, although in preliminary experiments I found that the cells deteriorated much more quickly if the glutathione and nucleotides were omitted. Both the internal solution and the ASW had osmolarities of approximately 1000 milliosmoles $/ \mathrm{kg}$, as measured by a Wescor, Inc. $5100 \mathrm{C}$ vapor pressure osmometer.

MEM and the internal solution were kept frozen until use. All solutions were filtered $(0.2 \mu \mathrm{m})$ immediately before use.

Forskolin was obtained from Calbiochem Behring Corp. (San Diego, CA). Stock solutions of 10 or $20 \mathrm{~mm}$ in ethanol were made. RO20-1724 was a gift to L. K. Kaczmarek from Dr. W. E. Scott of Hoffmann-La Roche, Inc. (Nutley, NJ). Stock solutions of 3.5 or $7 \mathrm{mM}$ in ethanol were used. Stock solutions of theophylline were made up at 10 to 50 $\mathrm{mM}$ in ASW. Aliquots of the stock solutions of the drugs were added to the bath to give the final concentration listed in the text. Control applications of ethanol had no effect on the cells.

\section{Results}

A-currents are present in the cultured, dialyzed bag cells. In most preparations in which A-currents have been studied, activation and inactivation of the $\mathrm{A}$-current occur at potentials which are much more negative than the potentials at which the other voltage-dependent currents are activated. This means that the A-current can be studied in relative isolation from

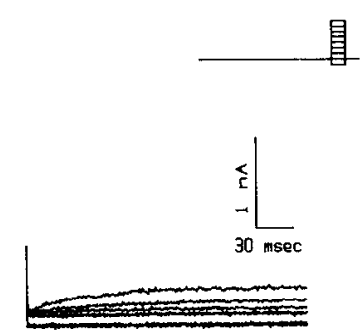

A

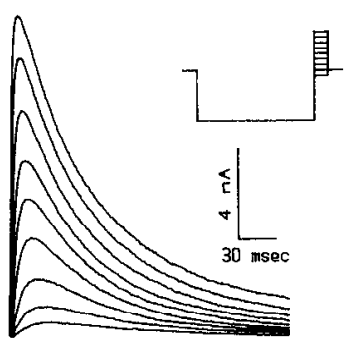

B

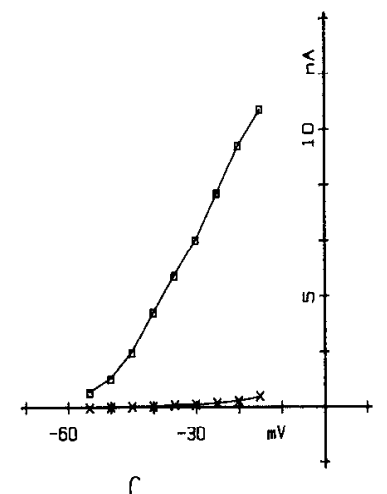

Figure 2. Isolation of A-currents in the bag cells. $A$, Currents seen during 280 -msec pulses from the holding potential $(-50)$ to $-50,-40$, $-35,-30,-25,-20$, and $-15 \mathrm{mV}$. Traces at -55 and -45 have been omitted for clarity but are included in the graph in $C$. $B$, Currents seen during 280-msec pulses to -55 (smallest current), $-50,-45,-40,-35$, $-30,-25,-20$, and $-15 \mathrm{mV}$ (largest current), following a 2.4-sec prepulse to $-95 \mathrm{mV}$. Note change of scale. $C$, Peak currents seen in $A$ $(X \mathrm{~s})$ and $B$ (squares) plotted against the pulse potential.

other currents, if the study is confined to these more negative potentials.

Figure 2 shows that A-currents are present in the cultured bag cells and can be studied in the voltage region more negative than $-15 \mathrm{mV}$ without significantly activating other currents. Figure $2 A$ shows the currents seen when the voltage is stepped from the holding potential $(-50 \mathrm{mV})$ to potentials between -55 and $-15 \mathrm{mV}$. At this holding potential, most of the A-current should be inactivated. Thus, most of these steps result in a small, square current deflection corresponding to a linear leak resistance of 250 megohms. (Some of these traces have been omitted for clarity.) At -20 and $-15 \mathrm{mV}$, very small, slowly developing outward currents are seen. Much larger, transient outward currents are seen during steps between -55 and -15 $\mathrm{mV}$ when inactivation is removed with a hyperpolarizing prepulse to $-95 \mathrm{mV}$ (Fig. $2 B$ ). These currents are quite similar to A-currents described in a number of other preparations. They activate very rapidly and decay exponentially; inactivation seems to be complete at all potentials where the current activates; and potassium seems to be the major charge carrier, as the currents have a reversal potential near the potassium equilibrium potential (see below), and as the same pattern of currents is seen in calcium-free, sodium-free, and chloride-free media (data not shown). As Figure 2 shows, the A-current is the predominant current seen in the potential region between -60 and $-15 \mathrm{mV}$ (see Fig. $2 \mathrm{C}$, which shows the peak current seen with and without the hyperpolarizing prepulse; also, note change of scale between Fig. 2, $A$ and $B$ ).

To study the effects of elevated intracellular cAMP levels on the A-currents, I have used bath application of forskolin, along with PDIs. Forskolin acts as a rapid, reversible, and receptorindependent ativator of adenylate cyclase in a variety of tissues 
(Seamon et al. 1981). In the bag cells, forskolin mimics the effects of cAMP derivatives in all aspects which have been tested so far. Specifically, forskolin, applied together with PDIs, has been found to initiate afterdischarges in intact bag cell clusters (Strumwasser et al., 1982) and to cause subthreshold oscillations and enhancement of the width and height of action potentials in cultured bag cells (Kaczmarek and Kauer, 1983). Forskolin also elevates cAMP levels in the intact bag cell cluster (S. DeRiemer and L. Kaczmarek, personal communication).

In the experiments described below, forskolin was used at a concentration of $100 \mu \mathrm{M}$. A PDI was always applied along with forskolin-either theophylline ( $1 \mathrm{mM})$ or, more often, the nonmethylxanthine PDI, R020-1724 (35 $\mu \mathrm{M})$. R020-1724 was preferred because it is thought to be a more specific PDI (Levitan and Norman, 1980; I. Levitan, personal communication). In other systems these concentrations of the drugs would be expected to give a maximal elevation of cAMP levels.

Forskolin speeds the time course of decay of the A-currents. The addition of forskolin and a PDI to the bath reliably produced a marked alteration in the A-currents. The effect is shown in Figure 3. The currents shown were measured during a 220 -msec pulse to the indicated potential, following a 450 msec prepulse to $-90 \mathrm{mV}$. In each pair of currents, the larger current is the control current, and the smaller is that seen after addition of the drugs to the bath.

The main effect of the forskolin and PDI is a reduction of the peak current at all potentials and an increase in the rate at which the current decays. This interpretation of the data presented in Figure 3 assumes that the currents seen after forskolin are modified A-currents and not, for example, the superposition of the A-current and some new, forskolin-induced inward current. This interpretation is supported by the data presented in Figure 4. This shows the results of an experiment exactly like that in Figure 3, but in which the external medium contained $170 \mathrm{~mm}$ no $\mathrm{Na}^{+}$. The slower, larger control currents and the smaller, faster-declining currents seen after forskolin have the same reversal potential of approximately $-23 \mathrm{mV}$. (The calculated Nernst potential for $\mathrm{K}^{+}$in this experiment is $-30 \mathrm{mV}$; in three other cells studied the reversal potential for the current was between -30 and $-25 \mathrm{mV}$. It was difficult to obtain records in high $\mathrm{K}^{+}$solutions, which often caused the cells to develop large leak conductances.) The transient currents seen after forskolin application are identified as modified A-currents because: (1) they have the same reversal potential and ionic dependence as the control A-currents; (2) like the control Acurrents, they are seen only after hyperpolarizing prepulses (see below); and (3) their general form is characteristic of A-currents, although the decay is more rapid than in control records.

The change in the inactivation kinetics seen in Figure 3 is examined in more detail in Figure 5. Here some of the pairs of currents shown in Figure 3 are replotted on a semilog scale (lower pair of currents in each panel) as well as on a linear scale (upper pair of currents in each panel). In the control records (larger current in each case) the falling phase of the current could be well fit by a single exponential, as has been described in most preparations. After forskolin and PDI, the falling phase of the current was more complex. It seemed to have two components, a predominant fast component and a second, smaller component with a time constant similar to the one measured in the control records. A natural interpretation of these observations is that a small fraction of the A-current channels is unchanged by forskolin treatment (i.e., has the same characteristics as the control), while most of the channels have been modified to (or replaced by) channels with faster inactivation kinetics. In accord with this view, the currents after forskolin and PDI were fit with the sum of two exponentials; the fast time constant was determined by the fit to the data and the slow time constant was constrained to have the same value as that fitted to the control data at the same voltage.

The exponential fits to the falling phase of the currents are also shown in Figure 5, superimposed on the currents in both the linear and semilog plots. The fits of single exponentials (in the case of the control records) or double exponentials (in the case of the forskolin/PDI records) were done by eye, as described under "Materials and Methods." The amplitudes of the exponential fits are shown in Figure 6A, and the time constants are shown in Figure $6 B$.

Figures 5 and 6 show that the decaying phase of the control
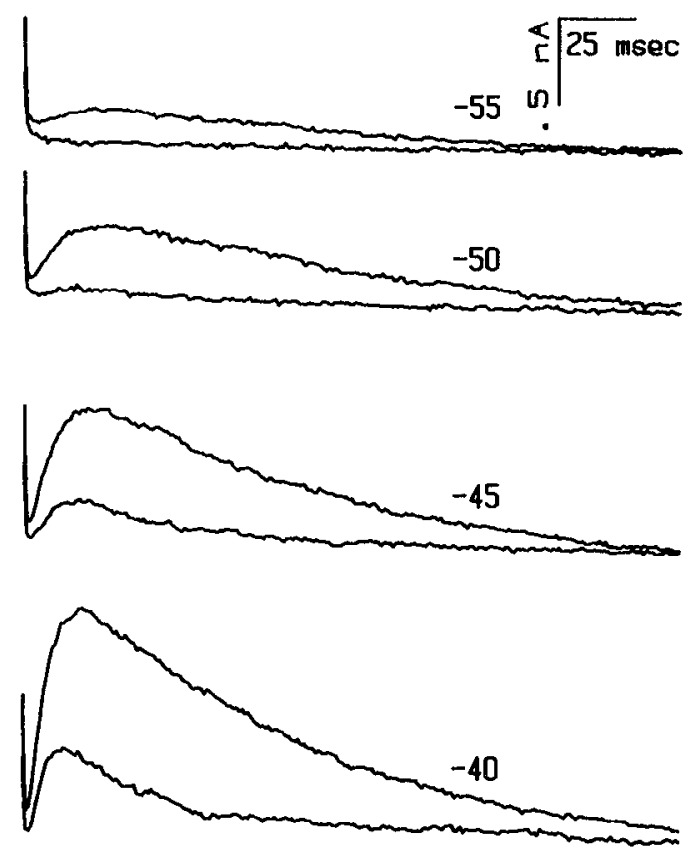
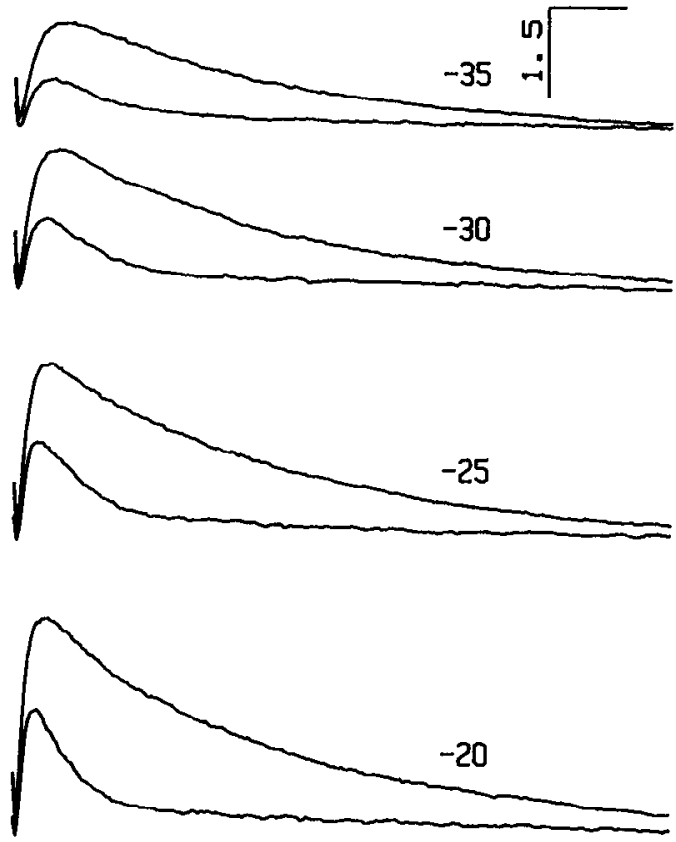

Figure 3. Effect of forskolin on the A-currents. Currents seen during 220-msec pulses to the indicated potential, after a 450 -msec prepulse to $-90 \mathrm{mV}$. The smaller current in each pair is that recorded 20 min after the addition of forskolin and RO20-1724 to the bath. Note change of scale between the left and right panels. 

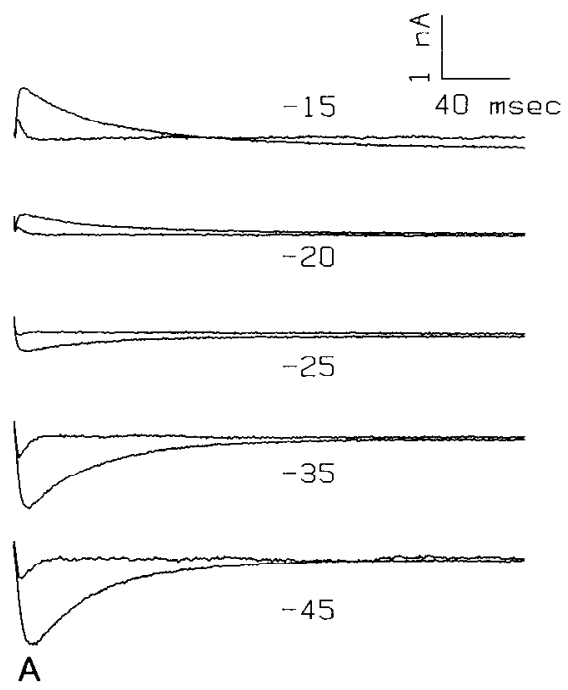

A

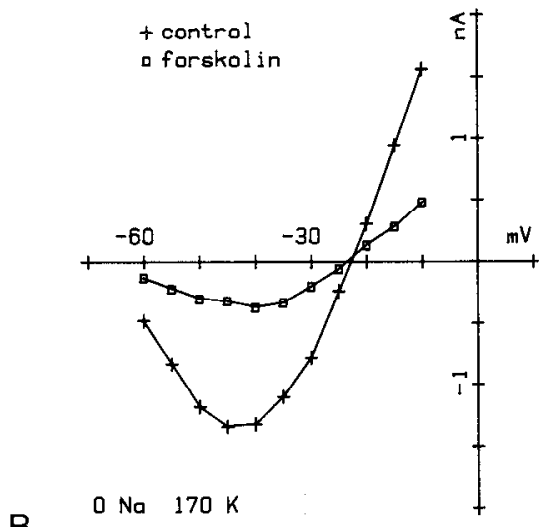

Figure 4. Effect of forskolin in high $\mathrm{K}^{+}$solution. A, Currents seen during 357 -msec pulses to the indicated potentials, following a 2.4 -sec prepulse to $-95 \mathrm{mV}$. The smaller, faster current in each trace is that seen 3 min after the addition of forskolin and RO20-1724 to the bath. The cell was in a bath solution in which the usual $460 \mathrm{mM} \mathrm{Na}{ }^{+}$was replaced by $160 \mathrm{mM} \mathrm{K}^{+}$and $300 \mathrm{mM} N$-methyl-D-glucamine. The ohmic portion of the leak current has been subtracted, and the first data point $(0.78 \mathrm{msec})$ containing the capacitative transient is not shown. $B$, Peak current seen during pulses such as those in $A$ is plotted against pulse potential, for control (crosses) and forskolin (squares) data. Points are connected by straight lines.

A-currents can be well fit by a single exponential with a time constant $(\tau)$ of approximately $80 \mathrm{msec}$. This time constant was essentially independent of voltage above $-40 \mathrm{mV}$. The currents after forskolin were well fit by the sum of two exponentials. The largest component of the two-exponential fit had a time constant of about $15 \mathrm{msec}$, again essentially independent of voltage above $-40 \mathrm{mV}$. The currents after forskolin were too small and noisy to allow an accurate determination of the slower time constant, but, as Figure 5 shows, the data could be quite reasonably described by assuming that the slower time constant had the same value as the control records.

Most of the depression of the peak current can be accounted for by the change in inactivation kinetics. Connor and Stevens (1971a) described the A-currents in gastropod neurons as the product of independent activation and inactivation terms. In such a description, if the only effect of forskolin were to change the inactivation time constant from 80 to $15 \mathrm{msec}$, a reduction in the peak current would be expected, especially since an inactivation process with a time constant of $15 \mathrm{msec}$ would show considerable overlap with the activation process (see Figs. 3 and 12). However, this scheme would also predict that the extrapolation to time zero of the exponental fits to the decaying phases of the currents would have the same value before and after forskolin, since this is a measure of the steady-state value of the activation term. Figure 5 shows that this is not the case; the exponential fits after forskolin have a value at time zero which is approximately $85 \%$ of the value in the control records. In every cell studied, including cells in which the amplitude of the A-current was quite stable before the application of forskolin, the amplitudes of the exponential fits had a smaller value at time zero after forskolin. This may simply indicate that the extrapolation is not meaningful (as, for example, if activation and inactivation are not independent). Alternatively, forskolin may have some small second effect: the modified channels could have a slightly smaller unit conductance as well as faster inactivation kinetics; a small fraction of channels could be completely turned off by forskolin; or the steady-state activation curve could be shifted to more positive voltages by forskolin. The data were not sufficient to rule out any of these possibilities.

The depression of peak current and the acceleration of the decaying phase of the current shown above were seen in 19 of 20 cells studied. The results of experiments in these 19 cells are summarized in Table I. The table summarizes parameters of the A-current measured at -30 or $-25 \mathrm{mV}$ (after a hyperpolarizing prepulse). The currents were analyzed by the method described above: control currents were fit by a single exponential, and currents after forskolin were fit by the sum of two exponentials, the slower of which was constrained to have the time constant seen in the control. The same results were seen when a different PDI, theophylline, was used. The A-currents were little altered by removal of sodium, chloride, or calcium from the ASW, and qualitatively normal forskolin effects were seen in these media.

In a few cells in which the forskolin effect was very large, the slow component of the current seen after forskolin could no longer be well fit by assuming it had the control time constant. Instead, the slow component seemed to be due to a very small, slowly developing (non-inactivating) outward current. An example of this current pattern is seen in Figure 8. In the four cells included in Table I which had large forskolin effects and were poorly fit by the two exponential method, the fraction of unmodified channels given in the table represents an estimate of the upper limit. In these four cells, the fraction of unmodified channels was estimated to be much less than $10 \%$.

In the one cell mentioned above as an exception, the Acurrents were completely unaffected by the addition of the forskolin and PDI. However, the control A-currents in this cell already had fast-decaying components; the decay was well described by the sum of two exponentials with time constants of 19 and $70 \mathrm{msec}$ and relative amplitudes of $76 \%$ and $24 \%$, respectively. In other words, the cell gave the appearance of being already fully modified by some cAMP-like mechanism.

With the one exception noted above, the A-currents measured in the dialyzed bag cells seemed quite stable and predictable. In the course of other experiments, or following control applications of ethanol, I could sometimes record the A-currents in a given cell for more than an hour and see very little change in the currents except for, in about $25 \%$ of the cells, a gradual reduction of the amplitude of the current. The alterations produced by forskolin as described above were never seen to occur spontaneously, or during control solution changes.

The time course of development of the forskolin effect. After the forskolin and PDI were added to the bath, the develoment of the drugs' effect was monitored by examining the A-current at a constant potential (usually $-25 \mathrm{mV}$ ) every 30 to $90 \mathrm{sec}$. With this protocol, I usually observed three time periods: a delay period, in which no effect was seen; a transition period; 

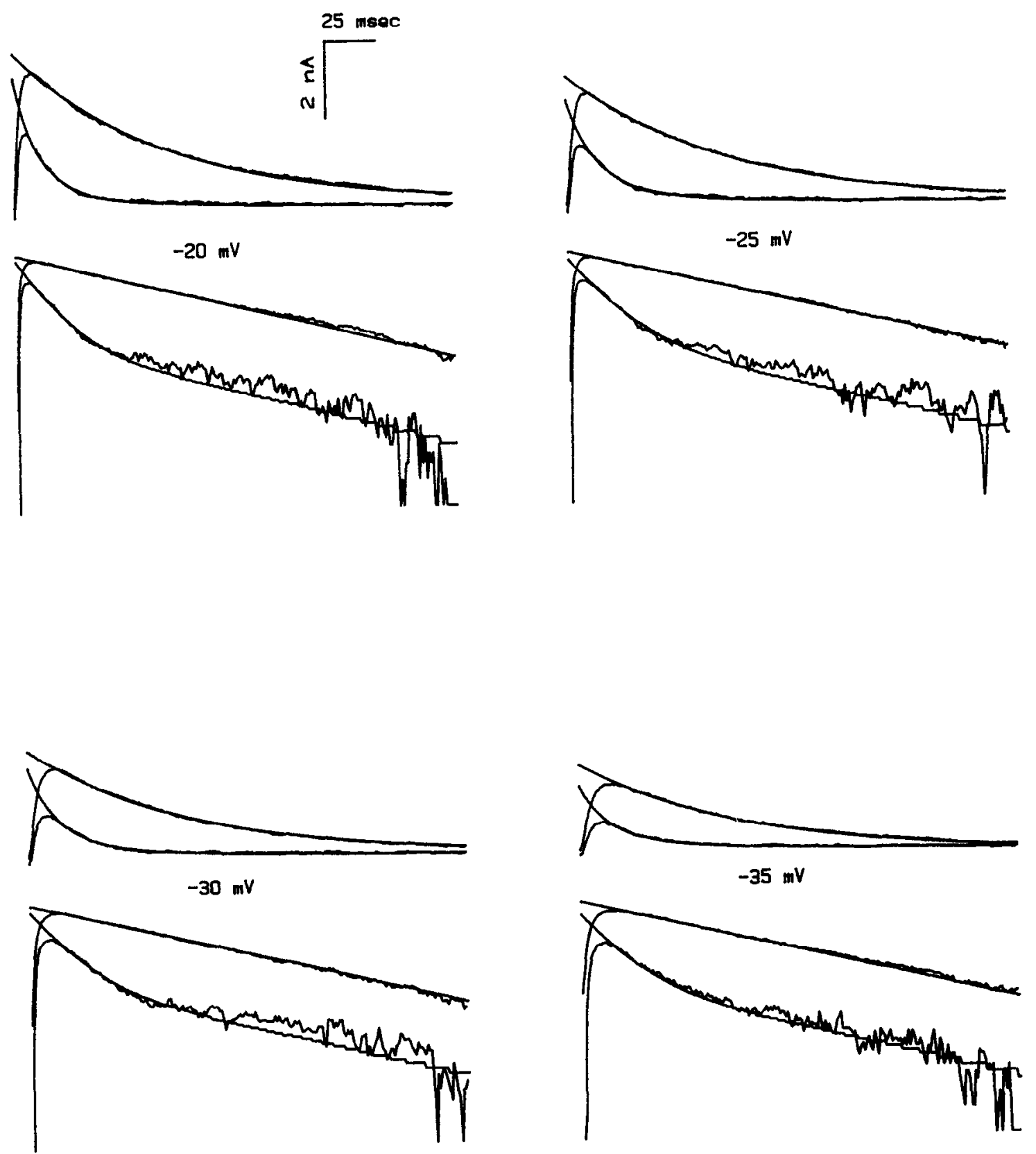

Figure 5. Analysis of the falling phase of the A-current. Some of the pairs of currents from Figure 3, replotted in both linear (top) and semilog (bottom) scales. 'The pulse potential is indicated for each panel. Superimposed on each current is the exponential curve fitted to the falling phase. In each panel, the larger (control) current is fit with a curve of the form $A 1^{*} \exp (-t / \tau 1)$, while the smaller (forskolin) current is fit with the sum of two exponentials, as described in the text. The first data point $(1 \mathrm{msec})$ in each record has been omitted (cf. Fig. 3).

and a period in which the effects were fully develoned and stable recordings again could be made. Figure 7 shows typical data taken during the development of the forskolin effect. During this transition period, the decaying phase of the Acurrent could be described by the sum of two exponentials with the same two time constants which were used to fit the data after the forskolin effect had stabilized. As the effect developed during the transition period, the decline in peak current, the decline in the amplitude of the slow component, and the increase in the amplitude of the fast component all occurred roughly in parallel (Fig. $7 \mathrm{C}$ ). This observation provides support for the idea that the modification of the individual channels is an all-or-none event. Implicit in the method of analysis used in Figure 5 is the idea that, at all times, only two kinds of channels are present, slowly inactivating and rapidly inactivat- ing. The supposition that the forskolin produces some kind of graded modification of the channel, in which the inactivation time constant could vary continuously, would not predict the observed time course of the development of the effect.

Quantitatively, the time course of the development of the forskolin effect varied considerably from cell to cell. In $70 \%$ of the cells, the delay before any effect was seen was 5 to $10 \mathrm{~min}$, and the effect had stabilized within $15 \mathrm{~min}$. However, at the extremes, in two cells an effect was seen in $30 \mathrm{sec}$, and in another no effect was seen until $15 \mathrm{~min}$ after the application of the drugs.

The forskolin effect can be reversed. Forskolin is thought to be a rapidly reversible activator of adenylate cyclase (Seamon et al., 1981). In three cells I was able to at least partially reverse the effects of the forskolin and PDI by washing the drugs out 


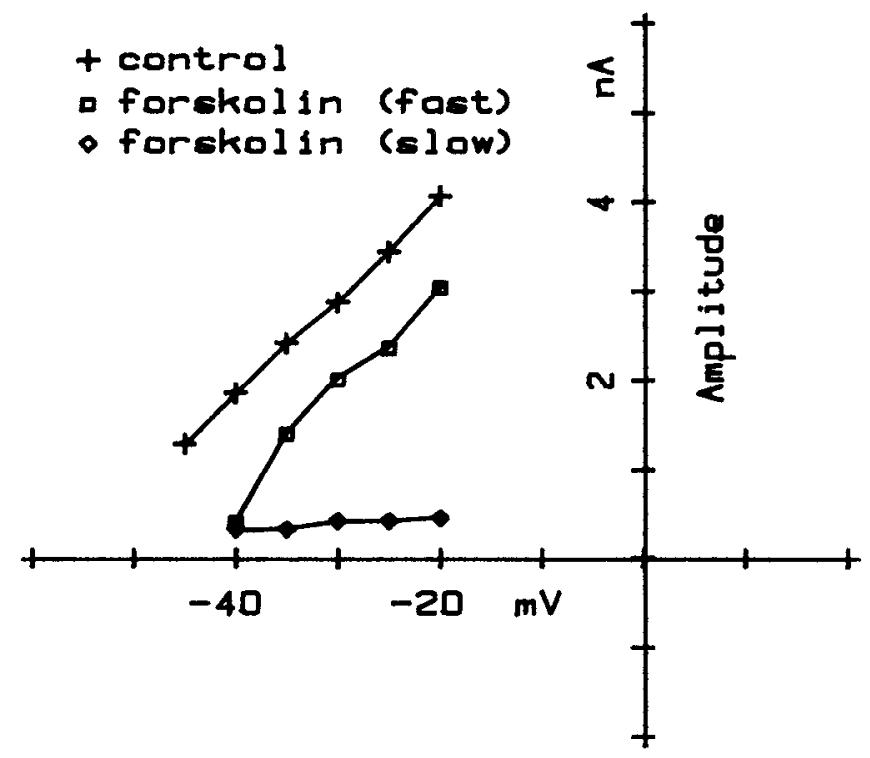

A

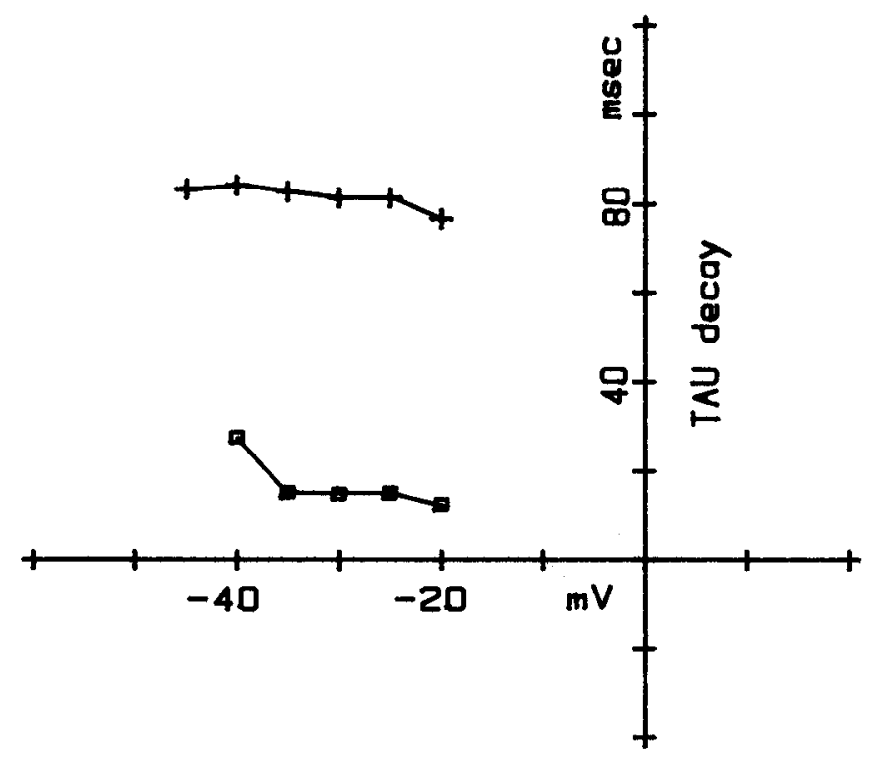

$\mathrm{B}$

Figure 6. Parameters of the exponential fits of the decaying phase of the A-currents. $A$, Amplitudes of the single exponential fit to the falling phase of the control currents (crosses), and of the fast (squares) and slow (diamonds) components of the double exponential fit to the forskolin currents shown in Figures 3 and $5 . B$, Value of the time constant used in the single exponential fit to the control data (crosses) and of the faster time constant in the double exponential fit to the forskolin data (squares). The slower time constant used in fitting the forskolin data is not plotted, since it was constrained to have the same value that was used to fit the control data taken at each potential.

of the bath. The reversal was incomplete in each case, either because there was still a small fast component in the decaying phase, or because the amplitude of the current did not completely recover. However, these cells had already been dialyzed for up to an hour before the drugs were washed out, and this may have accounted for my inability to completely reverse the drug's effects. To show that the forskolin/PDI effects described above are at least qualitatively reversible, I used a different experimental protocol in which the forskolin and PDI were added to the bath long before I began recording from the cell. Results of such an experiment are illustrated in Figure 8 . The currents shown are similar to those in Figure 3. In this case, however, the smaller, faster currents were recorded $3 \mathrm{~min}$ after the beginning of dialysis, at which time the cell had already been exposed to forskolin and R020-1724 for nearly $2 \mathrm{hr}$, whereas the larger, slower currents were recorded after a 10 min bath wash. In this cell, the first effects of the bath wash could be seen in less than $30 \mathrm{sec}$; longer washes were required in some cells. The currents after the wash decayed with a slow, single exponential time course, just like the control currents in the experiments described above, although there is, of course, no way of knowing whether the amplitude of the current also returned to its pre-forskolin value. This experiment also shows that the forskolin effect is probably similar in dialyzed and undialyzed cells, and that the effect is maintained for several hours (longer times were not tested) in the presence of the drugs.

Other measures also show inactivation is faster after forskolin. In the experiments described so far, the kinetics of inactivation have been studied by measuring the time constant for the decay of the current, $\tau_{\text {decay. }}$. To study the time course of inactivation at more negative potentials, where the A-current does not activate, the two conventional protocols shown in Figure 9, $A$ and $D$, were used. In both protocols, the degree of inactivation was assayed by measuring the peak outward current during a pulse to a potential V2 (usually, $-25 \mathrm{mV}$ ). Figure $9 A$ shows the method used to measure the time constant for removal of inactivation $\left(\tau_{\mathrm{rem}}\right)$. The voltage is stepped from the holding potential (where inactivation is complete) to some potential V1 where inactivation is incomplete. Plotting the peak A-current at $\mathrm{V} 2$ as a function of the duration $t 1$ of pulse VI gives a measure of the time course for removal of inactivation at the potential V1. This protocol is useful for studying inactivation kinetics at potentials where the amount of steady-state inactivation is small (i.e., where $h_{\infty}=1.0$ to 0.5 ; see below). In order to study inactivation kinetics in the potential region where $h_{\infty}$ is small $(0.5$ to 0 ), the protocol shown in Figure $9 D$ was used. The protocol is the same, except that the step to $V 1$ is preceded by a saturating prepulse to $-100 \mathrm{mV}$, which completely removes inactivation. One then observes the time course for development of inactivation at V1. Figure $9, B$ and $E$, shows the currents measured during the $\mathrm{V} 2$ pulse during these two protocols. The currents are displayed with a displacement to the right which is proportional to the duration of $t 1$, so that the time constants are represented by the envelope of peak currents. 'The graphs in Figure 9, $C$ and $F$, shows single exponential fits to these envelopes.

Ideally, one would like to study the effects of forskolin on inactivation kinetics by measuring $\tau_{\text {rem }}, \tau_{\text {dev }}$, and $\tau_{\text {decay }}$ over the entire voltage range, before and after forskolin. In practice, it is difficult to record from a single cell long enough to make all of these measurements. Comparing values measured in different cells was also difficult, due to the steep voltage dependence of the time constants. Instead, the following approach was taken.

In the protocols described above for measuring $\tau_{\text {dev }}$ or $\tau_{\text {rem }}$, the data are described by an equation of the form

$$
\frac{I(t)-I(\infty)}{I(0)-I(\infty)}=\exp (-t / \tau)
$$

in which $I$, the peak A-current measured at $-25 \mathrm{mV}$, is a function of $t$, the duration of the voltage pulse $\mathrm{V} 1$ at which the time constant is being measured. The equation assumes that inactivation is a single first-order process and that the peak of the current measured at the test potential $(-25 \mathrm{mV})$ is proportional to the degree of inactivation (Connor and Stevens, 1971a).

In order to examine the basic shape of the $\tau_{h}$ curve in a single 
TABLE I

Parameters of the A-current measured at -30 or $-25 \mathrm{mV}$ after a hyperpolarizing prepulse, before and after addition of forskolin and the indicated phosphodiesterase inhibitor (PDI)

As described in the text, the falling phase of the A-current in each control record was fit with a single exponential, with time constant $\tau_{\text {slow. }}$. The falling phase of the currents after forskolin was fit by an equation of the form:

$$
A M 1 * \exp \left(-t / \tau_{\text {slow }}\right)+A M 2 * \exp \left(-t / \tau_{\text {fast }}\right)
$$

where $\tau_{\text {slow }}$ was constrained to have the same value as the control record. This equation assumes that the total current measured during the falling phase is the sum of two currents: one "unmodified" current which decays with a time constant $\tau_{\text {slow, }}$ and one "modified" current which decays with a time constant $\tau_{\text {fast }}$. The amplitude $A M$ of each of these currents is the product of the driving force, number of channels, the single channel conductance, and the fraction of channels which are activated. The "fraction of unmodified channels" (last column) is the quantity $A M 1 /(A M 1+A M 2)$. This quantity provides a measure of the strength of the drug effects; it indicates the actual percentage of unmodified channels only if the activation parameters and single channel conductance are the same in modified and unmodified channels. Ionic substitutions in the modified seawaters were: $N$-methyl-glucamine for $\mathrm{NA}^{+}$, aspartate for $\mathrm{Cl}^{-}$, and $\mathrm{Mg}^{2+}$ for $\mathrm{Ca}^{2+}$.

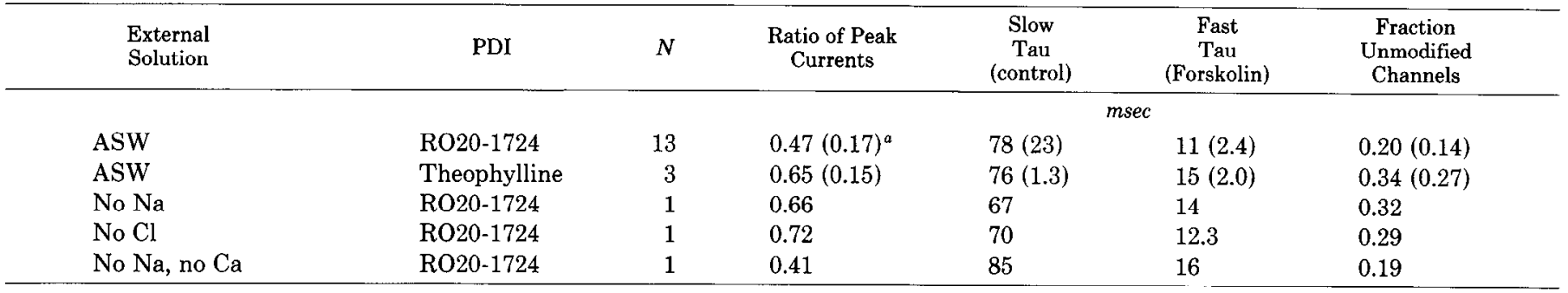

${ }^{a}$ Numbers in parentheses, standard deviations.

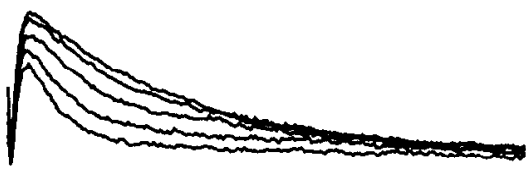

TIME SINCE FORSKOLIN/ROZO=

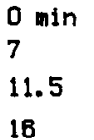

20.5

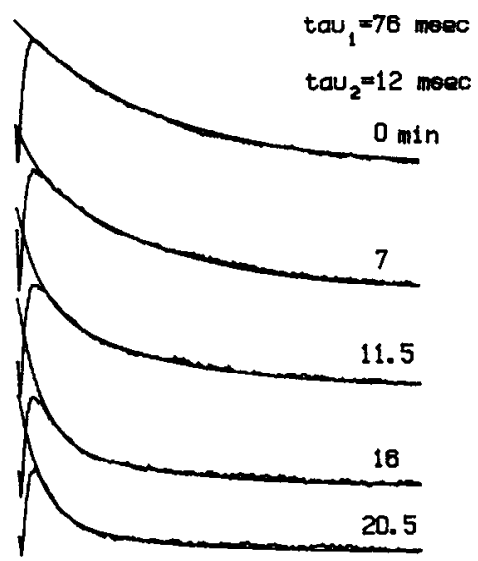

B

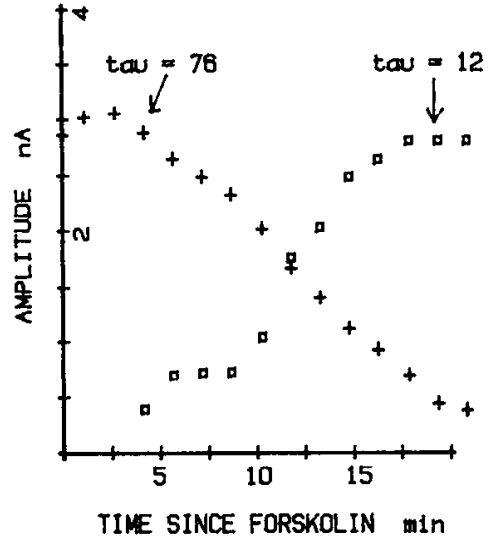

C

Figure 7. Time course of development of the forskolin effect. $A$, A-currents seen at $-25 \mathrm{mV}$, following a hyperpolarizing prepulse, at 0 (largest current), $7,11.5,16$, and 20.5 (smallest current) min after the addition of forskolin and RO20-1724. $B$, The same currents as in $A$, replotted with double exponentials fitted to the falling phase. The two time constants used to fit the currents were 76 and 12 msec. $C$, Amplitudes of the double exponential fits in $B$, plotted as a function of the time since addition of the drugs.

cell before and after forskolin, I made only three measurements for each voltage V1: $I(0), I(\infty)$, and $I(t 1)$. From these three points I computed the ratio given by the left-hand side of equation 1 . The time $t 1$ was selected (based on preliminary experiments) so that the measured ratio was in the range 0.3 to 0.6 . This meant that different values of $t 1$ were selected for different voltages, although at any given voltage the same value of $t 1$ was used before and after forskolin.

The results of such as experiment are shown in Figure 10. The measured ratios have been converted to effective time constants, according to equation 1 . The figure shows that the effective time constant (and hence the ratio) is smaller after forskolin treatment at all vollages examined. This means that, following a step to $\mathrm{V} 1$ of duration $t 1$, inactivation was always relatively closer to its final value after forskolin. This is a direct indication that inactivation processes are speeded up at all potentials by forskolin. The conclusion does not rely on the precise form of equation 1; it would hold even if removal and/ or development of inactivation were not single-order processes.

The method of calculating time constants from only three data points works surprisingly well. For example, if time constants are calculated from the corresponding three data points in the curves shown in Figure 9, the values obtained agree with the conventionally measured values shown in the figure within $10 \%$, even though these are obtained from 13 data points. It is possible to obtain accurate time constants from three data points only after doing preliminary experiments, which aie necessary both to ascertain that the processes studied are in fact single order and to select an appropriate value of $t 1$ for each voltage. In the preliminary experiments $(N=12)$ in which different portions of the $r-\mathrm{V}$ curve were examined using conventional protocols (Fig. 9), development and removal of inactivation were always faster after forskolin, and the effect was always more pronounced at more positive potentials. Measure- 


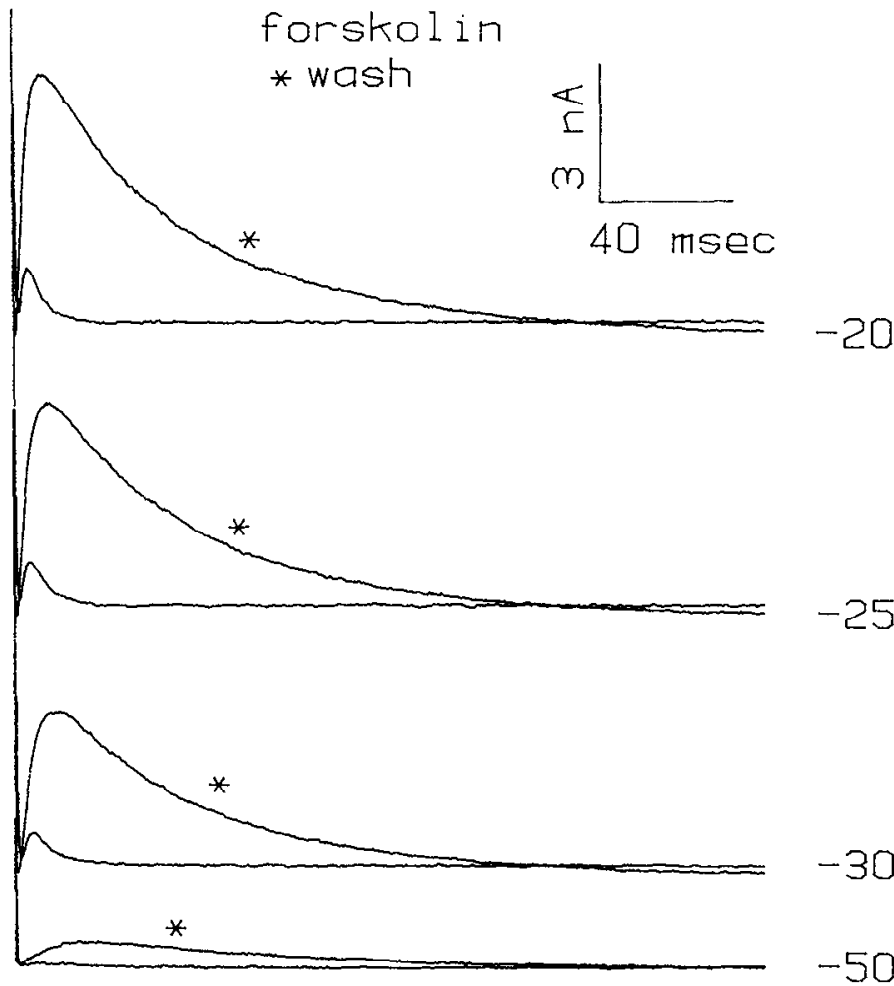

Figure 8. Reversal of the forskolin effect. Currents recorded during a 280 -msec pulse to the indicated potential, following a 2.4 -sec prepulsc to -95 . The smaller current in each pair was recorded within $3 \mathrm{~min}$ of the beginning of dialysis in a cell which had already been exposed to forskolin and RO20-1724 for $1 \mathrm{hr}$ and $45 \mathrm{~min}$. The larger current in each pair was recorded $10 \mathrm{~min}$ later, after a wash with drug-free ASW. Note that the currents cross late in the trace; there seems to be a very small, noninactivating outward current in the forskolin traces. This current was often observed in cells with large forskolin effects but was too small to study in detail.

ment of time constants by either method requires that, after forskolin, the fraction of unmodified channels is small. For the cell in Figure 10, this fraction was less than $10 \%$.

Also included in Figure 10 are values for $\tau_{\text {decay }}$, measured in the same cell according to the method detailed in Figure 5. Figure 10 shows agreement between the time constants measured by the decay and the development protocols at $-45 \mathrm{mV}$, where either protocol could be used. This agreement is less good after forskolin, but this may be because measurement of $\tau_{\text {dev }}$, but not of $\tau_{\text {decay }}$, is contaminated by the small remaining fraction of unmodified channels. In other cells, the time constant for removal of inactivation was seen to be equal (within $20 \%$ ) to the time constant for development of inactivation, in the voltage range $(-85$ to $-75 \mathrm{mV})$ in which both protocols could be used.

Figure 10 shows that inactivation processes are faster at all potentials after the application of forskolin. Proportionately, the effect is largest at more positive potentials. The location of the peak of the $\tau_{h}$ curve was little altered (although a shift of 5 $\mathrm{mV}$ or less would not have been detected) and was located near the midpoint of the $h_{\infty}$ curve both before and after forskolin (see below).

Steady-state inactivation is little altered by forskolin. The conventional protocol shown in the inset of Figure 11 was used to measure the steady-state voltage dependence of inactivation. The potential was stepped from the holding potential $(-50 \mathrm{mV})$ to various potentials V1, held there for $2.4 \mathrm{sec}$, then stepped back to the test potential V2 $(-25 \mathrm{mV})$, where the peak outward current measured. The relative peak current at V2 is plotted as

$$
\begin{aligned}
& \text { REMOVAL OF } \\
& \text { INACTIVATION }
\end{aligned}
$$$$
\text { DEVELDPMCNT of }
$$

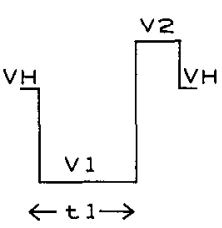

A
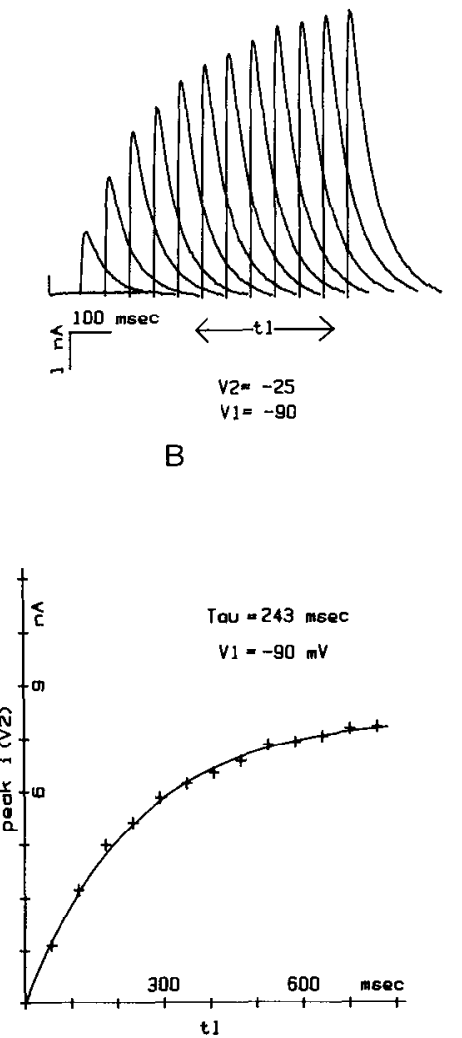

C

Figure 9. Measurement of time constants for removal and development of inactivation. $A$, Schematic diagram of protocol for measuring the time constant for removal of inactivation. $B$, Currents which flow during the V2 pulse $(-25 \mathrm{mV}, 262.5 \mathrm{msec}$; see $A)$ following pulses to V1 $(-90 \mathrm{mV})$ lasting $0,77,136,194,253,312,379,428,487,546,605$, 663 , and $721 \mathrm{msec}$. The currents are displayed with a displacement to the right proportional to $t 1$. The time scale refers both to the displacement and to the current records themselves. The first data point in each trace is omitted, and linear leakage currents have been subtracted. $C$, Graph of peak current as a function of $t 1$, taken from the records in $B$. The points have been fit by eye with a single exponential. $D$, Protocol for measuring the time constant for development of inactivation. $E$ Currents which flow during the V2 pulse $(-25 \mathrm{mV}, 195 \mathrm{msec}$; see $D)$ following 800 -msec prepulses to $-100 \mathrm{mV}$ and pulses to $-60 \mathrm{mV}$ lasting $0,23,47,70,94,117,164,187,211,234$, and $258 \mathrm{msec}$. Currents are displayed as in $B$. Data in $B$ and $E$ are taken from different cells. $E$, Graph of peak current as a function of $t 1$, taken from the records in $E$ fit by eye with a single exponential. The base line of the exponential was set to 0 based on measurement of the V2 current after a 2.5-sec pulse to $-60 \mathrm{mV}$; this current could not be included in $E$ without drastically altering the scale. $\mathrm{VH}$ (holding potential) was $-50 \mathrm{mV}$ in both experiments.

a function of V1 in Figure 11. The data are taken from same the experiment used to make Figure 10. As Figure 11 shows, the steady-state inactivation curve is little altered by forskolin. The curve in Figure 11 has the form

$$
h_{\infty}=(1+\exp [(\mathrm{V}-\mathrm{V} 0) / N])^{-1}
$$




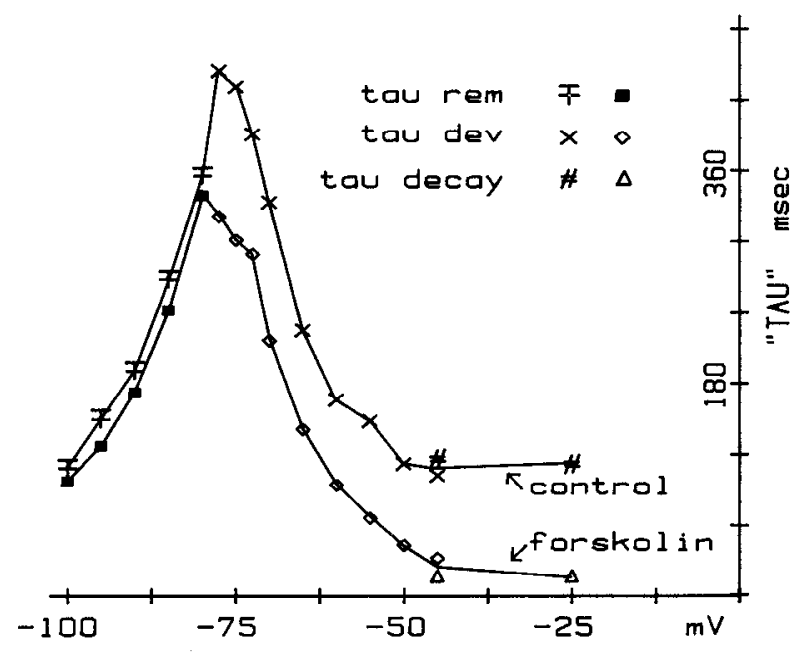

Figure 10. Complete $\tau_{h}$ curve in a single cell, before and after application of forskolin and RO20-1724. Values of $\tau_{\text {rem }}$ and $\tau_{\text {dev }}$ were estimated from three data points, as described in the text.

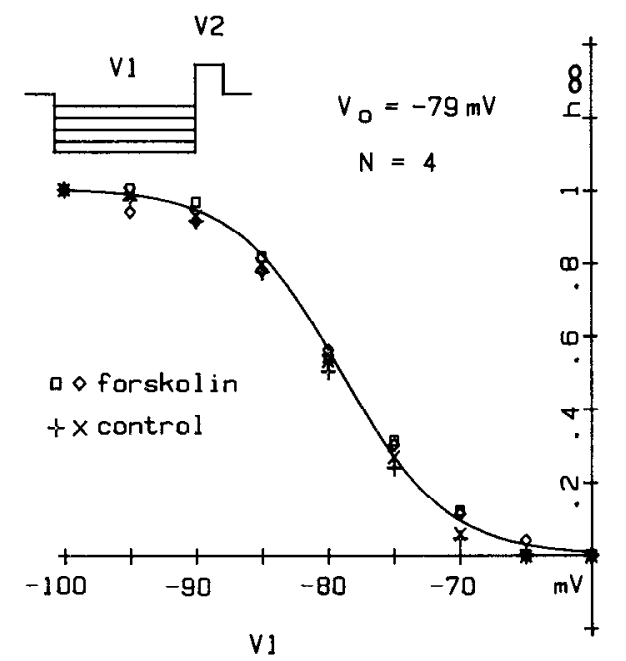

Figure 11. Steady-state parameters of inactivation. Data are taken from the same cell as in Figure 10. The inset shows the voltage protocol, as described in the text. Peak current during a 260-msec depolarization to $\mathrm{V} 2(-25 \mathrm{mV})$ is plotted as a function of V1, the value of the voltage during the 2.4-sec prepulse. Data were normalized at $-100 \mathrm{mV}$. Control ( $X \mathrm{~s}$ and crosses) and forskolin measurements (squares and diamonds) bracket the measurements of inactivation time constants used to make Figure 10. See the text for explanation of the curve.

in which $N$ is a measure of the steepness of the curve, and V0 gives the location of the curve along the $\mathrm{V}$ axis. In 11 cells in which the steady-state inactivation curve was measured before and after application of forskolin and PDI, the average values of V0 ( $\pm \mathrm{SD})$ were $-82.4 \mathrm{mV}$ (3.3) before forskolin and -80.6 $\mathrm{mV}$ (3.5) after forskolin. Average values of $N$ were $4.7 \mathrm{mV}$ (0.46) before, and $4.7 \mathrm{mV}(0.84)$ after forskolin. A value of 4 for the steepness of the curve has been reported for A-currents in other preparations (Neher, 1971; Hagiwara et al., 1981).

I was not able to study the inactivation process at potentials much more negative than $-100 \mathrm{mV}$, as the cells would not tolerate such hyperpolarizations even briefly.

$A$-current activation processes are similar before and after forskolin. The data in Figure 3 show that the basic voltage range over which activation of the A-current occurs in the control and forskolin records. There is more depression of the peak current at the more negative potentials (see the traces at -55 to -45 , for example). However, if one were to describe the current using a model which had independent activation and inactivation processes, this result might be expected even if the activation process were unaltered by the forskolin: after forskolin, the inactivation process is much faster than the activation process at the most negative potentials, and hence little current would be seen at those potentials.

Figure 12 shows that the basic voltage dependence of the Acurrent activation kinetics is very similar before and after forskolin. The time to half-peak decreases as the pulse potential increases, and the values are the same in the control and forskolin records (Fig. 12A) In Figure $12 B$, the currents seen during activating voltage pulses are shown on an expanded time scale. The control currents have been scaled to have the same peak value as the currents seen after forskolin. The current reaches a peak at a somewhat earlier time after forskolin, although again, one expects this given the faster rate of inactivation seen after forskolin. In short, the data do not force the conclusion that forskolin alters what would tranditionally be called the activation process, although small shifts in the activation curve by forskolin could not be excluded unless a more detailed kinetic model of the channel were developed. I believe

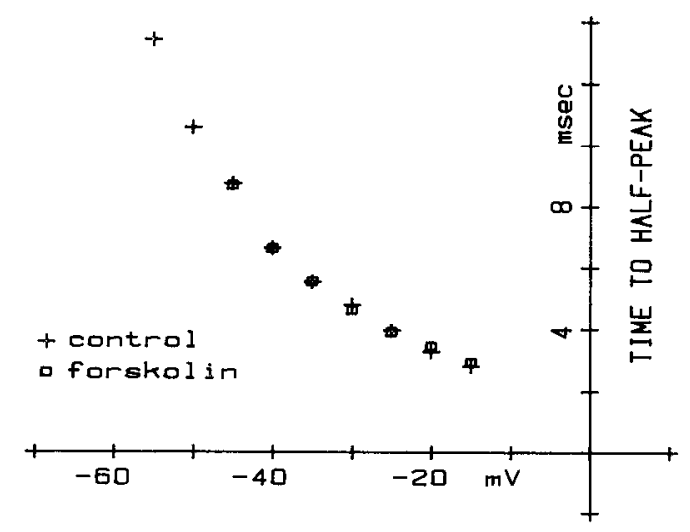

A

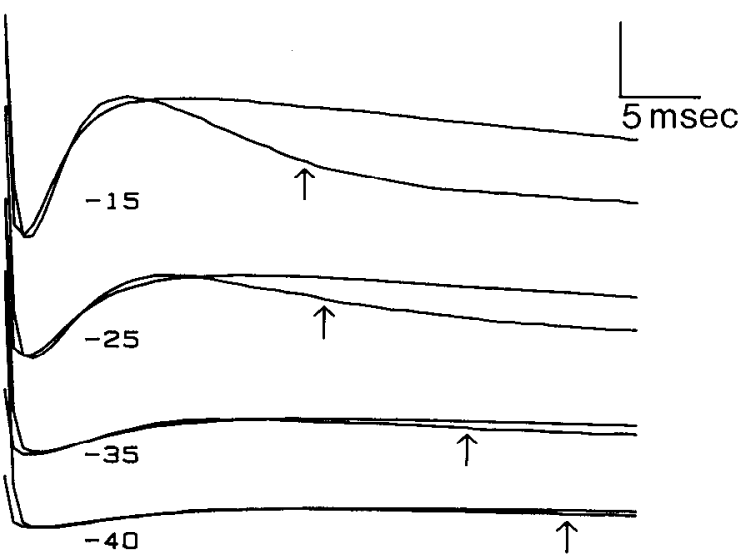

B

Figure 12. Time course of activation before and after forskolin. Currents were measured during $280-\mathrm{msec}$ pulses to the indicated potentials, following a $2.4-\mathrm{sec}$ prepulse to $-95 \mathrm{mV}$. $A$, The time required for the current to reach half its peak value is plotted against the pulse potential. Crosses, control; squares, after forskolin and RO20-1724. B, Currents seen during the indicated pulse potentials are shown on an expanded time base. Data from these currents are included in $A$. The scale bar $(3 \mathrm{nA})$ refers to the currents seen after forskolin (arrows); control currents have been scaled to have the same peak value. Scale factors were $0.21(-40), 0.27(-35), 0.34(-25)$, and $0.41(-15)$. 
that studies at the single-channel level are the next logical step in developing such a model and in studying how the kinetics of the A-current channels are changed during the application of forskolin.

\section{Discussion}

The primary finding of this study is that the inactivation kinetics of the A-currents are greatly speeded by extracellular application of forskolin and a phosphodiesterase inhibitor (PDI) in cultured bag cells.

The changes seen can be reasonably attributed to the activity of the adenylate cyclase system. The existence of the enzymes of the adenylate cyclase system in the bag cells is well established, and the effects on the A-currents were seen with various combinations of three very different chemicals (forskolin, RO20-1724, and theophylline); elevation of cAMP is the only effect that these are known to have in common. In addition, in a two-microelectrode voltage clamp study of the cultured bag cells, Kaczmarek and Strumwasser (1984) have found that extracellular application of the membrane-permeant cAMP analogue 8-benzylthio,6- $N$-butyl cAMP also causes a marked increase in the rate of decay of the A-currents. Hence this effect has been seen with drugs that act at the level of the adenylate cyclase-, the phosphodiesterase-, and the cAMPdependent protein kinase.

From a functional point of view, the finding that the Acurrents after forskolin are smaller and inactivate more quickly seems very reasonable. In other cells in which it has been studied, the A-current seems to be the prodominant current which determines the interspike interval in repetitively firing cells. This is because, in most cells, the A-current is partially inactivated at the resting potential. Some of this inactivation is removed during the hyperpolarizing afterpotential, and the time course of the following slow depolarization (during the interspike interval) is strongly determined by the amplitude, activation kinetics, and inactivation kinetics of the A-current (see Connor, 1978). One of the hallmarks of the afterdischarge in bag cells is the transformation of a cell which is incapable of firing repetitively to one which fires repetitively for up to an hour. Such a transformation is qualitatively consistent with the forskolin-induced modifications of the A-current reported here.

It remains to be seen what role these modifications of the Acurrent have in the afterdischarge of bag cells in intact cell clusters. It is well established that cAMP concentrations increase during the afterdischarge and, therefore, the A-current inactivation kinetics presumably will be speeded up in the intact system. However, the cAMP levels produced by forskolin are probably higher than those seen in vivo, and the effects reported in this paper may be larger than those that would be seen during a normal afterdischarge. In addition, the intracellular milieu will be very different in an intact cell. Voltage clamp experiments of the type reported here are difficult to perform in the intact system, due to the extensive neuronal processes and the high degree of coupling between the cells. However, it might be possible to study the effects of cAMP on the electrical properties of intact bag cells by using a voltage clamp method which would measure only the current flowing through well-clamped soma membrane.

The A-current is not the only current which can be modified by elevations of cAMP in the bag cells. In the work mentioned above, Kaczmarek and Strumwasser (1984) also reported the development of a region of negative slope resistance near the threshold; after application of the cAMP analogue, there is a net inward current near $-30 \mathrm{mV}$. This current was small $(0.05$ $\mathrm{nA}$ ) and, if present in my experiments, might have been obscured by the much larger A-currents. Kaczmarek and Strumwasser (1984) also found a reduction of other outward currents, at more depolarized potentials. In the dialyzed cultured cells, I have also seen reduction of outward currents (other than the A-current) by forskolin and PDIs (work in progress). It may be that the cAMP-induced changes in these other outward currents are responsible for the changes in action potential shape seen during the afterdischarge, whereas the modifications of the A-current reported here are necessary to allow rapid repetitive firing.

Modulation of the A-current has been reported in some other systems. Alkon et al. (1981) found that the A-current of a Hermissenda photoreceptor has a smaller amplitude and faster inactivation kinetics in animals whose phototaxic behavior has been reduced with an associative learning paradigm. These modifications of the A-current are thought to be caused by prolonged depolarizations and calcium influx. Barker et al. (1983) reported that thyrotropin-releasing hormone (TRH) reduces the $\mathrm{A}$-current in cloned pituitary cells. TRH does not affect the kinetics of the current, but acts by shifting its steadystate activation curve to more positive potentials. A simple reduction in the amplitude of the A-current is seen in starfish oocytes during maturation induced by 1-methyladenine (Moody and Lansman, 1983).

A-currents have been reported in a wide variety of excitable tissues and in many species. (For review, see Thompson and Aldrich (1980). The following discussion excludes transient outward currents which are known to be calcium dependent.) These calcium-independent A-currents share certain general features, but their kinetic properties show a great deal of interspecies and intra-organism variability. A good example of the extreme values is given by Connor (1978): in crustacean axons, the inactivation time constants are voltage dependent, ranging from $1.5 \mathrm{msec}$ at $-20 \mathrm{mV}$ to $3 \mathrm{msec}$ at $-60 \mathrm{mV}$; neurons of the mollusk Anisodoris have inactivation time constants of $60 \mathrm{msec}$ which are completely independent of voltage. Similarly, the activation time constants in Anisodoris are slower than those of the crustacean axon, and only the latter are voltage dependent.

Variability between different neurons in a single organism has been studied by Serrano (1982), who compared the Acurrents in several different identified neurons of the mollusk Archidoris. She found that the steady-state curves for both activation and inactivation had very similar voltage dependences in all cells studied, but that the time constant for decay of the current at $-30 \mathrm{mV}$ and the time constant for removal of inactivation at $-80 \mathrm{mV}$ varied systematically (up to 4 -fold) between different identified cells. Smaller decay time constants were associated with smaller time constants for the removal of inactivation. Hence, in these cells, there seem to be A-currents which (due to differentiation) have similar steady-state properties but different inactivation kinetics. This bears an interesting resemblance to the effect of forskolin on the bag cells.

In most known examples of hormonal modulation of ionic channels, the effect of the hormone is to increase or decrease the size of the ionic current (for review, see Siegelbaum and Tsien, 1983. For other examples of channels with hormonally modulated kinetic properties, see Tsien, 1974, and Reuter et al., 1982). The work of Serrano (1982) and the results reported in this paper suggest that it may be a characteristic property of the A-current protein(s?) that its inactivation kinetics can be rather dramatically modified. It is interesting to note that the kinetic properties of the A-current can also be modified genetically. Studies of the Drosophila Shaker gene locus, which is thought to code for a structural protein related to the Acurrent, have revealed that some mutations cause inactivation and removal of inactivation to be speeded up (Salkoff and Wyman, 1981). Another mutation abolishes the voltage-dependence of the A-current inactivation kinetics (Salkoff, 1982).

Many examples of neuromodulation (including the bag cell afterdischarge) involve changes in the patterns of repetitive 
firing. Also, some of the most obvious differences found between different neurons in a given organism are found in their patterns of repetitive activity. Given the important role of the Acurrent in determining repetitive firing capabilities, it is not surprising that mechanisms exist to modulate its properties both acutely and during differentiation. The A-current may prove to be an interesting "preparation" in which to study neuromodulation and differentiation at a single-channel level.

\section{References}

Adams, P. R., D. A. Brown, and A. Constanti (1982) Pharmacological inhibition of the M-current. J. Physiol. (Lond.) 332: 223-262.

Akaike, N., K. S. Lee, and A. M. Brown (1978) The calcium current of Helix neuron. J. Gen. Physiol. 71: 509-532.

Alkon, D., I. Lederhendler, and J. Shoukimas (1982) Primary changes of membrane currents during retention of associative learning. Science 215: 693-695.

Barker, J. L., B. Dufy, D. Owen, and M. Segal (1983) Excitable membrane properties of cultured CNS neurons and clonal pituitary cells. Cold Spring Harbor Symp. Quant. Biol. 48: 259-268.

Connor, J. A. (1978) Slow repetitive activity from fast conductance changes in neurons. Fed. Proc. 37: 2139-2145.

Connor, J. A., and C. F. Stevens (1971a) Voltage clamp studies of a transient outward membrane current in gastropod neural somata. J. Physiol. (Lond.) 213: 21-30.

Connor, J. A., and C. F. Stevens (1971b) Predictions of repetitive firing behaviour from voltage clamp data on an isolated neuron soma. J. Physiol. (Lond.) 213: 31-53.

Hagiwara, S., K. Kusano, and N. Saito (1961) Membrane changes of Onchidium nerve cell in potassium-rich media. J. Physiol. (Iond.) 155: 470-489.

Hagiwara, S., S. Yoshida, and M. Yoshii (1981) Transient and delayed potassium currents in the egg cell membrane of the coelenterate, Renilla koellikeri. J. Physiol. (Lond.) 318: 123-141.

Hamill, O. P., A. Marty, E. Neher, B. Sakmann, and F. J. Sigworth (1981) Improved patch-clamp techniques for high-resolution current recording from cells and cell-free membrane patches. Pflügers Arch. 391: $85-100$.

Heller, E., L. K. Kaczmarek, M. W. Hunkapiller, L. E. Hood, and F. Strumwasser (1980) Purification and primary structure of two neuroactive peptides that cause bag cell afterdischarge and egg-laying in Aplysia. Proc. Natl. Acad. Sci. U. S. A. 77: 2328-2332.

Hodgkin, A. L., and A. F. Huxley (1952) The dual effect of membrane potential on sodium conductance in the giant axon of Loligo. J. Physiol. (Lond.) 16: 497-506.

Jennings, K. R., L. K. Kaczmarek, R. M. Hewick, W. J. Dreyer, and F. Strumwasser (1982) Protein phosphorylation during afterdischarge in peptidergic neurons of Aplysia. J. Neurosci. 2: 158-168.

Kaczmarek, L. K., and J. Kauer (1983) The role of calcium entry in the prolonged refractory pcriod that follows afterdischarge in pepti dergic neurons of Aplysia. J. Neurosci. 3: 2230-2239.

Kaczmarek, L. K., and F. Strumwasser (1981) The expression of long lasting afterdischarge by isolated Aplysia bag cell neurons. J. Neurosci. 1: 626-634.

Kaczmarek, L. K., and F. Strumwasser (1984) A voltage clamp analysis of currents underlying cAMP-induced membrane modulation in isolated peptidergic neurons of Aplysia. J. Neurophysiol. 52: 340-349.

Kaczmärek, L. K., K. Jennings, and F. Strumwasser (1978) Neurotransmitter modulation, phosphodiesterase inhibitor effects, and cAMP correlates of afterdischarge in peptidergic neurites. Proc. Natl. Acad. Sci. U. S. A. 75: 5200-5204.

Kaczmarek, L. K., M. Finbow, J. P. Revel, and F. Strumwasser (1979) The morphology and coupling of Aplysia bag cells within the abdominal ganglion and in cell culture. J. Neurobiol. 10:535-550.

Kaczmarek, L. K., K. R. Jennings, F. Strumwasser, A. C. Nairn, U.
Walter, F. D. Wilson, and P. Greengard (1980) Microinjection of catalytic subunit of cyclic AMP-dependent protein kinase enhances calcium action potentials of bag cell neurons in cell culture. Proc. Natl. Acad. Sci. U. S. A. 77: 7487-7491.

Kehoe, J., and A. Marty (1980) Certain slow synaptic responses: Their properties and possible underlying mechanisms. Annu. Rev. Biophys. Bioeng. 9: 437-465.

Kostyuk, P. G., O. A. Krishtal, and V. I. Pidoplichko (1975) Effect of internal fluoride and phosphate on membrane currents during intracellular dialysis of nerve cells. Nature 257: 691-693.

Kostyuk, P. G. (1984) Intracellular perfusion of nerve cells and its effects on membrane currents. Physiol. Rev. 64: 435-454.

Kupferman, I., and E. R. Kandel (1970) Electrophysiological properties and functional interconnections of two symmetrical neurosecretory clusters (bag cells) in abdominal ganglion of Aplysia. J. Neurophysiol. 33: $865-876$

Levitan, I. B., and W. B. Adams (1981) Cyclic AMP modulation of a specific ion channel in an identified nerve cell: Possible role for protein phosphorylation. Adv. Cyclic Nucleotide Res. 14: 647.

Levitan, I. B., and J. Norman (1980) Different effects of cAMP and cGMP derivatives on the activity of an identified neuron: Biochemical and electrophysiological analysis. Brain Res. 187: 415-429.

Madison, D. V., and R. A. Nicoll (1982) Noradrenaline blocks accommodation of pyramidal cell discharge in the hippocampus. Nature 299: 636-638.

Moody, W. J., and J. B. Lansman (1983) Developmental regulation of $\mathrm{Ca}^{++}$and $\mathrm{K}^{+}$currents during hormone-induced maturation of starfish oocytes. Proc. Natl. Acad. Sci. U. S. A. 80: 3096-3100.

Neher, E. (1971) Two fast transient current components during voltage clamp on snail neurons. J. Gen. Physiol. 58: 36-53.

Reuter, H. (1983) $\mathrm{Ca}^{++}$channel modulation by neurotransmitters, enzymes, and drugs. Nature 301: 569-574.

Reuter, H., C. F. Stevens, R. W. Tsien, and G. Yellen (1982) Properties of single calcium channels in cardiac cell culture. Nature 297: 501504

Salkoff, L. B. (1982) Mutant $\mathrm{K}^{+}$channels: Greatly reduced voltage sensitivity of inactivation rate. Soc. Neurosci. Abstr. 8: 729.

Salkoff, L. B., and R. J. Wyman (1981) Genetic modification of potassium channels in Drosophila Shaker mutants. Nature 293: 228.

Seamon, K. B., W. Padgett, and J. W. Daly (1981) Forskolin: Unique diterpene activator of adenylate cyclase in membranes and in intact cells. Proc. Natl. Acad. Sci. U. S. A. 78: 3363-3367.

Serrano, E. E. (1982) Variability in molluscan neuron soma currents. Ph.D. thesis, Stanford University, Stanford, CA.

Siegelbnaum, S. A., and R. W. Tsien (1983) Modulation of gated ion channels as a mode of transmitter action. Trends Neurosci. 6: 307312.

Siegelbaum, S. A., J. S. Camardo, and E. R. Kandel (1982) Serotonin and cAMP close single $\mathrm{K}^{+}$channels in sensory neurones. Nature 299: 413-417.

Stern, J., and J. E. Lisman (1982) Internal dialysis of Limulus ventral photoreceptors. Proc. Natl. Acad. Sci. U. S. A. 79: 7580.

Strumwasser, F. L., L. K. Kaczmarek, A. Y. Chiu, E. Heller, K. R. Jennings, and D. P. Viele (1980) Peptides controlling behavior in Aplysia. In Peptides: Integrators of Cell and Tissue Functions, F. E. Bloom, ed., pp 197-218, Raven Press, New York.

Strumwasser, F. L., L. K. Kaczmarek, and K. R. Jennings (1982) Intracellular modification of membrane channels by cAMP-mediated protein phosphorylation in peptidergic neurons of Aplysia. Fed. Proc. 41: 2933-2939.

Thompson, S. H., and R. A. Aldrich (1980) Membrane potassium channels. In The Cell Surface and Neuronal Function. C. W. Cotman, G. Poste, and G. L. Nicolson, eds., pp. 50-78, Elsevier/North Holland Biomedical Press, Amsterdam.

Tsien, R. W. (1974) Mode of action of chronotropic agents in cardiac Purkinje fibers. Does epinephrine act by directly modifying the external surface charge? J. Gen Physiol. 64: 320-342. 